Research Article

\title{
Intelligent Control Using Metaheuristic Optimization for Buck-Boost Converter
}

\author{
P. Chanjira $(\mathbb{D})$ and S. Tunyasrirut \\ Faculty of Engineering, Pathumwan Institute of Technology, 833 Rama 1 Road, Wangmai, Pathumwan, \\ Bangkok 10330, Thailand \\ Correspondence should be addressed to S. Tunyasrirut; satean@pit.ac.th
}

Received 24 June 2020; Accepted 27 July 2020; Published 14 August 2020

Academic Editor: Jiun-Wei Horng

Copyright (C) 2020 P. Chanjira and S. Tunyasrirut. This is an open access article distributed under the Creative Commons Attribution License, which permits unrestricted use, distribution, and reproduction in any medium, provided the original work is properly cited.

\begin{abstract}
This research aims to introduce an intelligent controlling system of windmill-generated voltage connected to a load of $12 \mathrm{~V}$. As natural wind speed lacks consistency, the resultant irregular voltage can lead to system damage. In the experiment, a buck-boost converter is not only designed to control such voltage but also tuned by intelligent methods. It is very challenging to control the system. PI controller is developed using metaheuristic optimization, an artificial fish-swarm algorithm (AFSA). In testing, the buck-boost converter is controlled by the PI controller at a reference voltage of $14 \mathrm{~V}$ and supplied with an input voltage $\left(V_{\text {in }}\right)$ in the range of 5-100V. The result shows that, even with inconstant $\left(V_{\text {in }}\right)$, the system can effectively control the reference voltage at $14 \mathrm{~V}$.
\end{abstract}

\section{Introduction}

Energy is quite essential for modern life: almost every human activity nowadays needs energy, most commonly in the forms of heat and electricity, with the main source currently being fossil fuel formed by burying biomass, e.g., natural gas and coal. Not only are these sources of energy limited and nonrenewable, but such energy production also causes pollution to the environment, including the atmosphere, i.e., the greenhouse effect [1]. Therefore, it is necessary to change the energy usage behavior and to seek alternative energy.

One of the alternatives attracting attention is wind power, as the wind is clean, pollutionless, and ubiquitous. It is also continually available both day and night. Production of wind energy involves conversion of kinetic energy into electrical energy: the turbine turns the airflow's kinetic energy into mechanical power and drives the permanent magnet synchronous generator (PMSG). The obtained alternating current later goes through a rectifier and becomes direct current. However, the natural wind speed is not constant, causing the electric pressure gained from PMSG to exhibit high variation, which leads to inconstant electrical supply and discontinuous operation [2]; the same has been stated in a previous study by Chandan and Chayapathy. Furthermore, in the event of low wind speed, it is insufficient to recharge batteries. For this reason, a buck-boost converter is introduced for maintaining voltage [3].

In a precedent work, Mittal and Arora have simulated windmills in MATLAB/Simulink [4] using PMSG and employed a buck-boost converter to control the electric pressure through such circuits as a chopper and inverter. This conforms with Porselvi and Muthu's designed wind energy conversion system with boost converter and CHBMLI with single DC input, which retains the voltage at the DC link suitable for the fluctuating wind pressure [5]. Moreover, another study by Kamalakkannan and Arunkumar utilizes a buck-boost converter in upholding the voltage output at the DC-DC link [6]. Both suggest the necessity of controlling the changing electric tension at the DC-DC link onto an appropriate level for the gridconnected system.

In this study, a buck-boost converter is thus chosen as a switching device to adjust the unstable electric pressure at the DC-DC link to a reference voltage of the system [7], since the buck-boost converter possesses the function of increasing and decreasing electric pressure, which resembles 
the natural wind speed. Valenzuela and Alarcon proposed the control of a boost DC-DC power converter using the new controller under constrained input, which is the duty cycle, the physically admissible values. Moreover, the uncertain supply voltage and unmeasurable inductor current are used as an observer for the proposed control law [8]. Ortigoza et al. used a two-stage control design which performs the sensorless angular velocity trajectory tracking task for the buck power converter/DC motor system. Not only is a firststage controller based on the differential flatness property of the DC-motor model, but also a second-stage controller is based on flatness property on the buck power converter model to provide the input voltage to the DC motor [9]. Licea et al. presented a reconfigurable topology which consists of a reconfigurable buck, boost, and buck-boost DCDC converter. Furthermore, a robust controller is designed by polytopic representation, and a Lyapunov based switched stability analysis of the closed-loop system is presented. The experimental results show that the robust stability under arbitrarily fast parameter variations and reconfiguration changes [10].

However, a proper standard value of PI controller was tuned by various approaches. One interesting approach is the optimization algorithm, a mathematical process to obtain an optimal value. A supporting study by Siano and Citro suggests using multiobjective particle swarm optimization to design a fuzzy-logic controller for buckboost converters with inconstant change of voltage [11]. The result obtained the quantity or numeric value of the problems set, to be further used as the suitable standard value. Similarly, Jalilvand et al. apply advanced particle swarm optimization, a sampling evolutionary algorithm efficient in finding optimal solutions in adjustment of PID controller's parameters [12]. This is in accordance with Tehrani et al., who propose a theory and an adaptation of the multipurpose strength Pareto evolutionary algorithm (SPEA). This controlling method dynamically responds to the required PID sorting coefficient [13]. In controlling PI controller, thus, a controller is required to control the standard PI. Furthermore, Liu and Hsu adopt the particle swarm optimization (PSO) technique for a static synchronous compensator (STATCOM) in finding a suitable standard value of intelligent PI controller [14]. Ultimately, Çınar and Akarslan design an intelligent battery charger controller for PV panels due to the its various capabilities [15]. Hence, a PI controller is operated to control the farming load system, the battery charger system, and the system which can supply to grid-connected system. Yau et al. apply two-stage system which implements maximum power point tracking and optimal charge control of Li-ion battery. They use PI to control charge controller parameters. In determining the optimum parameters, the intelligent algorithms, PSO, and genetic algorithms (GAs) are utilized. The optimal parameter results for the controller of PSO have better performance than GA [16].

The purpose of this research is to design a buck-boost converter for controlling the reference electric pressure at $14 \mathrm{~V}$ and to develop a PI controller enhanced with metaheuristic optimization, artificial fish-swarm algorithm (AFSA), as an intelligent voltage controlling system of an $18 \mathrm{~A}$ load for continual usage.

\section{Materials and Methods}

\subsection{Theories}

2.1.1. Wind Energy. Wind is one of the clean and renewable natural sources. Wind formation results from solar radiation upon Earth. Receiving and absorbing unequal amounts of heat leads to difference in temperature and atmospheric pressure between geolocations. Air then lifts up in areas with high temperature or low atmospheric pressure and is replaced by the air from cooler areas or higher atmospheric pressures. This movement of air mass causes the wind and its motion's kinetic energy is harvestable. The wind energy has been harnessed more and more, especially in producing electrical power. In Thailand, when compared to other countries, such advantages of wind energy have been little brought into use [17].

Winds in Thailand are seasonal, following rather precise annual pattern of occurrence. To exemplify, monsoons, e.g., Southeast Asian monsoon, occur with unchanged direction and last for the entire season. As Asia covers a large area, the temperature and atmospheric pressure between the inland and coastal regions vastly differ, leading to distinct wind direction in each season.

2.1.2. Buck-Boost Converter. The buck-boost converter is a type of circuit which transforms one electric pressure to another, either higher or lower, within the same circuit. Its function is based on the principle of cutting the input direct voltage into parts using a switching device, controlled by signals of the pulse width modulation (PWM) at a particular frequency. The control frequency which yields the buckboost converter's highest efficiency is reached when the time period $(T)$ is the lowest, at 100 times the switching rate, as shown in Figure 1 [18].

The operation of a buck-boost converter can be divided into two modes, according to the condition of the power switch device:

(1) Buck-Boost Converter Switch, Closed Circuit Mode. From Figure 2, the current flows from the electrical power source through the switch and the inductor $(L)$ cause the inductor to store power in the form of magnetic field [19], explained by the following equation:

$$
\begin{gathered}
V_{L}=V_{S}=L \frac{\mathrm{d} i_{L}}{\mathrm{~d} t}, \\
\frac{\mathrm{d} i_{L}}{\mathrm{~d} t}=\frac{V_{S}}{L}=\frac{\Delta i_{L}}{\Delta t},
\end{gathered}
$$

where $V_{S}$ is the voltage drops across the supply and $V_{L}$ is the voltage drops across the inductor.

Hence, $\Delta i_{L} / \Delta t$ is the rate of change of the current in closed switch, where $t_{\text {on }}=D T_{s}$ and $D$ is the duty cycle at $t_{\text {on }}$ : 


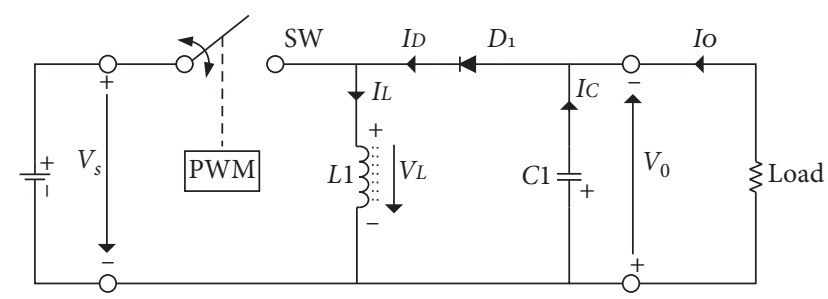

Figure 1: Buck-boost converter circuit.

$$
\frac{\Delta i_{L}}{\Delta t}=\frac{\Delta i_{L}}{D T_{S}}=\frac{V_{S}}{L}
$$

such that

$$
\Delta i_{L(\text { close })}=\left(\frac{V_{S}}{L}\right) D T_{S}
$$

(2) Buck-Boost Converter Switch, Open Circuit Mode. Figure 3 shows the operation mode after the closed circuit condition. When the circuit is closed, the energy accumulated in the inductor creates self-induction, reversing the direction of electric pressure across the inductor and transforming itself into an electrical supply. Nonetheless, the current still flows through the inductor in the same direction as in the closed circuit. The diode is forward-biased, as in the closed circuit condition $[12,13]$, as described by the following equation:

$$
\begin{aligned}
& V_{L}=V_{S}=L \frac{\mathrm{d} i_{L}}{\mathrm{~d} t}, \\
& \frac{\mathrm{d} i_{L}}{\mathrm{~d} t}=\frac{V_{0}}{L}=\frac{\Delta i_{L}}{\Delta t},
\end{aligned}
$$

where $V_{S}$ is voltage drops across the supply and $V_{L}$ is voltage drops across the inductor. $V_{0}$ is an output of buck-boot converter

Hence, $\Delta i_{L} / \Delta t$ is the rate of change of the current in open switch where $t_{\text {off }}=(1-D) T_{S}$, and $D$ is the duty cycle at $t_{\text {off }}$.

$$
\begin{aligned}
\frac{\Delta i_{L}}{\Delta t} & =\frac{\Delta i_{L}}{(1-D) T_{s}}=\frac{V_{0}}{L}, \\
\Delta i_{L \text { (open) }} & =\left(\frac{V_{0}}{L}\right)(1-D) T_{S} .
\end{aligned}
$$

Combining (3) and (6), a change rate of the current can be rewritten as

$$
\begin{aligned}
\Delta i_{L(\text { close })}+\Delta i_{L(\text { open })} & =0, \\
\left(\frac{V_{S}}{L}\right) D T_{S}+\left(\frac{V_{0}}{L}\right)(1-D) T_{S} & =0 .
\end{aligned}
$$

Rearranging (8), $V_{o}$ is denoted by

$$
V_{0}=-V_{S}\left(\frac{D}{1-D}\right), \quad D \neq 0 .
$$

2.1.3. Designed Circuit of Buck-Boost Converter. The equivalent circuit design of the buck-boost converter is shown in Figure 4.

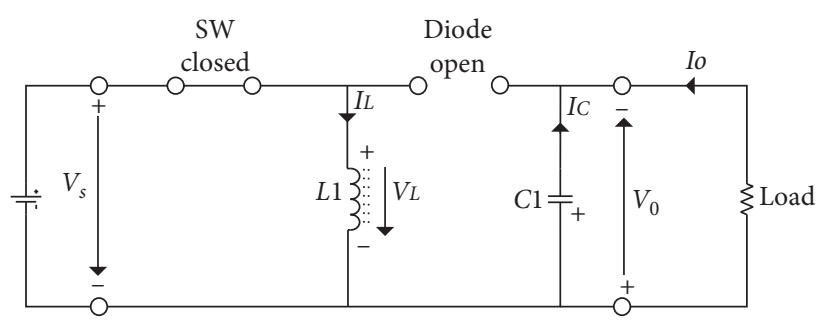

FIgURE 2: Buck-boost converter switch, closed circuit.

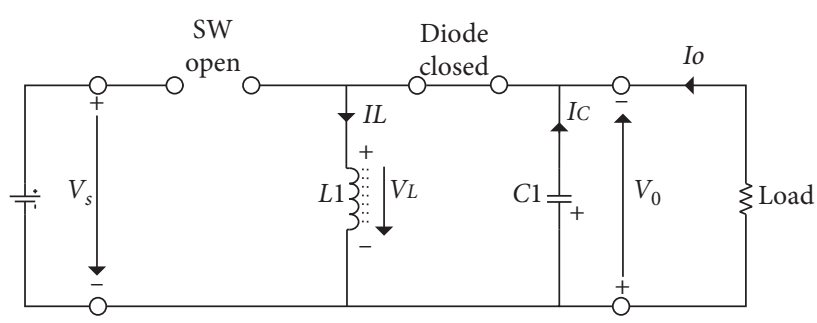

FIGURE 3: Buck-boost converter switch, open circuit.

Based on Figure 4, the parameters designed for buckboost converter are shown in Table 1 .

According to Figure 4 the designed circuit of buck-boost converter can receive an input voltage $\left(V_{\text {in }}\right)$ in the range $5-100 \mathrm{~V}$ with standard value $V_{\text {out }}$ at $14 \mathrm{~V}$ compatible with a load of $18 \mathrm{~A}$. The load resistance is calculated as $0.78 \Omega$ according to Ohm's law. All these parameters are revised, while the voltage input to the buck-boost converter ranges from $0 \mathrm{~V}$ to $100 \mathrm{~V}$ as the input should be lower or higher than the reference pressure $V_{\text {out }}=14 \mathrm{~V}$. The output response of the buck-boost converter uses an inductance of $33.6 \mathrm{mH}$, a capacitance of $110 \mu \mathrm{f}$, and PWM signals for driving IGBT constant switching frequency at $4 \mathrm{kHz}$. The state vector for the buck-boost converter is defined as

$$
x(t)=\left[\frac{I_{L}}{V_{C}}\right],
$$

where $I_{L}$ is the current through the inductor and $V_{C}$ is the voltage across the capacitor. For the given duty cycle of $78 \%$, the system is represented by the following set of continuous time state spaces equations:

$$
\begin{aligned}
& \dot{x}(t)=A x(t)+B V_{S}(t), \\
& y(t)=C x(t)+D V_{S}(t),
\end{aligned}
$$

where $\dot{x}$ is the state vector, $V_{S}$ is the source vector, and $A, B, C, D$ are the state coefficient matrices. The state model of the buck-boost converter is provided by the two modes as follows:

The closed circuit mode is defined as

$$
\dot{x}(t)=A_{1} x(t)+B_{1} V_{S}(t) .
$$

The open circuit mode is written as

$$
\dot{x}(t)=A_{2} x(t)+B_{2} V_{S}(t)
$$


where

$$
\begin{aligned}
& A_{1}=\left[\begin{array}{cc}
0 & 0 \\
0 & \frac{-1}{R C}
\end{array}\right] ; \\
& A_{2}=\left[\begin{array}{cc}
0 & \frac{-1}{L} \\
\frac{1}{C} & \frac{1}{R C}
\end{array}\right] ; \\
& B_{1}=\left[\begin{array}{l}
\frac{1}{L} \\
0
\end{array}\right] ; \\
& B_{2}=\left[\begin{array}{l}
0 \\
0
\end{array}\right] .
\end{aligned}
$$

The state space model is of the following form:

$$
\dot{x}(t)=[A][x]+[B][u],
$$

where

$$
\begin{aligned}
& B=d b_{1}+(1-d) B_{2}, \\
& B=d b_{1}+(1-d) B_{2}, \\
& A=\left[\begin{array}{cc}
0 & \frac{d-1}{L} \\
\frac{1-d}{C} & \frac{-1}{R C}
\end{array}\right], \\
& B=\left[\begin{array}{l}
\frac{d}{L} \\
0
\end{array}\right] .
\end{aligned}
$$

Then $d, L$ and $C$ are substituted as shown in

$$
\begin{aligned}
& A=\left[\begin{array}{cc}
0 & -6.5476 \\
2000 & -11655
\end{array}\right], \\
& B=\left[\begin{array}{c}
23.214 \\
0
\end{array}\right] .
\end{aligned}
$$

Hence, the transfer function of the buck-boost converter is shown as

$$
G(s)=\frac{46428}{0.001 s^{2}+11655 s+1.31} .
$$

From Figure 5, the process gain is defined as

$$
K_{S}=\frac{\text { Output }}{\text { Input }} \text {. }
$$

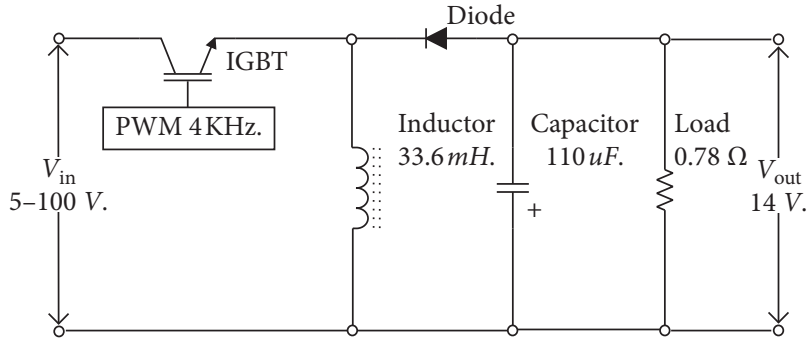

FIgURE 4: Designed circuit of buck-boost converter.

TABLe 1: Parameter setting for a buck-boost converter.

\begin{tabular}{lcc}
\hline No. & Parameters & Values \\
\hline 1 & Voltage input $\left(V_{\text {in }}\right)$ & $5-100 \mathrm{~V}$ \\
2 & Output voltage $\left(V_{\text {out }}\right)$ & $14 \mathrm{~V}$ \\
3 & Duty cycle & $78 \%$ \\
4 & Switching frequency $(f)$ & $4 \mathrm{kHz}$ \\
5 & Load $(R)$ & $0.78 \Omega$ \\
6 & Inductance $(L)$ & $33.6 \mathrm{mH}$ \\
7 & Capacitance $(C)$ & $110 \mu \mathrm{f}$ \\
\hline
\end{tabular}

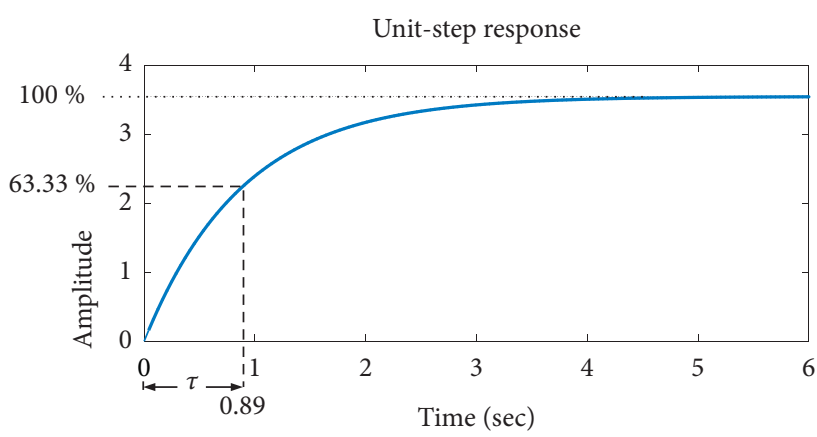

FigURE 5: Open loop response of buck-boost convertor.

In substituting variables in (21), the equation yields $K_{S}=3.54$. According to Figure $5, \tau=0.89, K_{S}$ is a process gain, and $\tau$ is a time constant.

2.1.4. PI Control of First-Order Systems. Suppose that the process can be described by the following first-order model [20]:

$$
G p(s)=\frac{K_{S}}{\tau s+1}
$$

In substitution, the transfer function of the controller for buck-boost converter is rewritten as

$$
G p(s)=\frac{3.54}{0.89 s+1}
$$

Figure 6 illustrates the first-order model buck-boost converter design. 


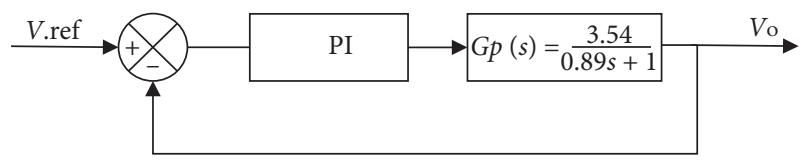

Figure 6: Closed-loop control of the first-order system.

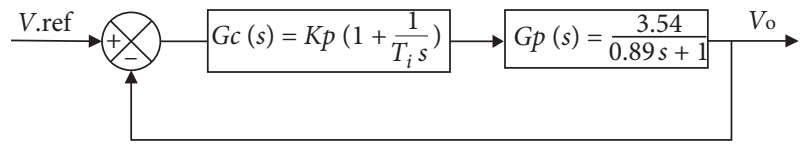

Figure 7: Closed-loop control system with PI controller designed by pole placement method.

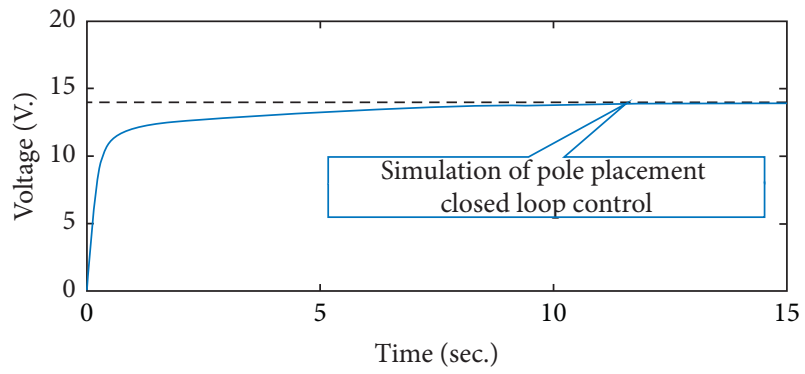

FIGURE 8: Simulation of closed-loop control using PI controller designed by pole placement method.

The two parameters are presented, the process gains $K_{s}$ and the time constant $\left(T_{i} s\right)$. By controlling this with the PI controller [21] provided as

$$
G c(s)=K_{p}\left(1+\frac{1}{T_{i} s}\right),
$$

a buck-boost converter design with PI controller is achieved.

According to Figure 7, a second-order closed-loop system is obtained as

$$
G \gamma(s)=\frac{G c(s) G p(s)}{1+G c(s) G p(s)} .
$$

The two closed-loop poles can be chosen arbitrarily for a suitable choice of the gain $K_{p}$ and the integral time $T_{i}$ of the controller. The poles are given by the characteristic equation [13]

$$
1+G p(s) G c(s)=0 .
$$

Suppose that the desired closed-loop poles are characterized by their relative damping $\varsigma$ and frequency $\omega$; the desired characteristic equation then becomes

$$
s^{2}+2 \zeta \omega s+\omega^{2}=0
$$

Substitution yields

$$
\tau T_{i} s^{2}+\left(K_{S} K_{p}+1\right) T_{i} s+K_{S} K_{p}=0 .
$$

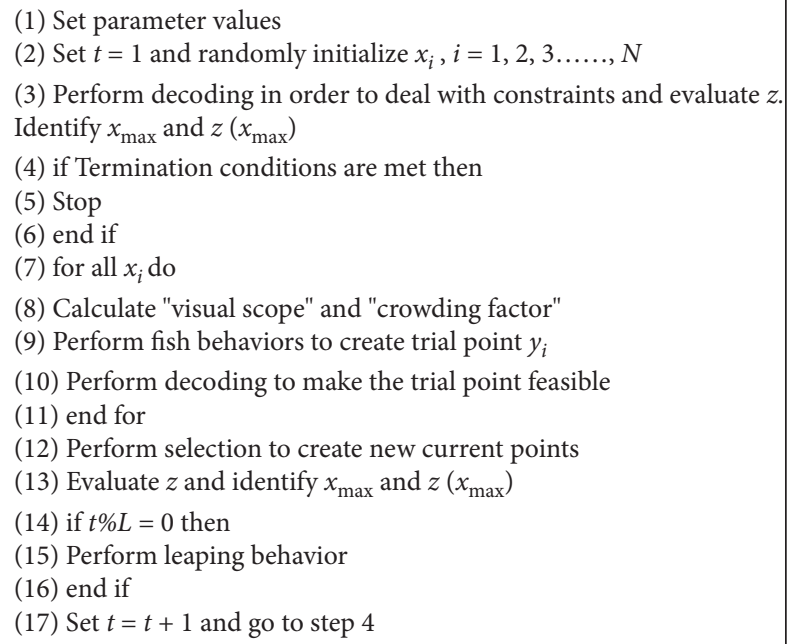

FIGURE 9: The binary version of the AFSA search algorithm.

TABLE 2: the parameters set for AFSA in tuning the PI controller [23].

\begin{tabular}{lc}
\hline Parameters of AFSA & Value \\
\hline Number of vehicles & $30-50$ \\
Time of trying & 1000 \\
Visual area & 5 \\
Factor of crowding degree & 0.618 \\
One step & 1.5 \\
Maximum number of iterations & 5000 \\
\hline
\end{tabular}

The coefficients of these two characteristic equations for determining $K_{p}$ and $T_{i}$ are written as

$$
\begin{gathered}
K_{p}=\frac{2 \zeta \omega \tau-1}{K_{s}}, \\
T_{i}=\frac{2 \zeta \omega \tau-1}{\omega^{2} \tau},
\end{gathered}
$$

where $\zeta=0.707$; note that in order to have positive controller gains, it is necessary that the chosen bandwidth $(\omega)$ be larger than $1 / 2 \xi \tau$. If $\omega$ is very large, the integration time $T_{i}$ is given by

$$
T_{i}=\frac{2 \zeta}{\omega}
$$

and $\omega$ is hereby calculated as

$$
\omega=\frac{1}{2 \xi \tau}
$$

From the design, $\zeta=0.707$ and then $\omega=(1 /(2 \times 0.707 \times 0.89))$ so that $\omega=0.795$.

In defining $\omega_{n}=5 \omega \omega_{n}=5 \omega$,

$$
\omega_{n}=3.795 \text {. }
$$


TABLe 3: Parameter setting of AFSA.

\begin{tabular}{|c|c|c|c|c|c|c|c|c|c|}
\hline \multirow{2}{*}{ No. } & \multicolumn{3}{|c|}{ AFSA, 30 vehicles } & \multicolumn{3}{|c|}{ AFSA, 40 vehicles } & \multicolumn{3}{|c|}{ AFSA, 50 vehicles } \\
\hline & $K_{p}$ & $T_{i}$ & Cost function & $K_{p}$ & $T_{i}$ & Cost function & $K_{p}$ & $T_{i}$ & Cost function \\
\hline 1 & 1.24 & 0.495 & 0.554 & 1.34 & 0.503 & 0.5387 & 1.45 & 0.495 & 0.5619 \\
\hline 2 & 1.26 & 0.523 & 0.4926 & 1.34 & 0.488 & 0.5753 & 1.38 & 0.573 & 0.4034 \\
\hline 3 & 1.23 & 0.506 & 0.5274 & 1.36 & 0.431 & 0.7608 & 1.39 & 0.640 & 0.3178 \\
\hline 4 & 1.27 & 0.407 & 0.8597 & 1.31 & 0.539 & 0.4604 & 1.46 & 0.505 & 0.5361 \\
\hline 5 & 1.27 & 0.480 & 0.5943 & 1.34 & 0.527 & 0.4846 & 1.4 & 0.534 & 0.4714 \\
\hline 6 & 1.3 & 0.361 & 1.1194 & 1.36 & 0.456 & 0.7050 & 1.44 & 0.450 & 0.6931 \\
\hline 7 & 1.27 & 0.492 & 0.5644 & 1.36 & 0.465 & 0.6421 & 1.31 & 0.615 & 0.3465 \\
\hline 8 & 1.24 & 0.482 & 0.5888 & 1.37 & 0.451 & 0.6872 & 1.4 & 0.570 & 0.4083 \\
\hline 9 & 1.28 & 0.487 & 0.5757 & 1.32 & 0.562 & 0.4204 & 1.38 & 0.548 & 0.4458 \\
\hline 10 & 1.27 & 0.452 & 0.6791 & 1.35 & 0.447 & 0.7004 & 1.43 & 0.483 & 0.5918 \\
\hline 11 & 1.27 & 0.505 & 0.5318 & 1.35 & 0.460 & 0.6562 & 1.37 & 0.599 & 0.3672 \\
\hline 12 & 1.27 & 0.475 & 0.6070 & 1.34 & 0.544 & 0.4529 & 1.4 & 0.573 & 0.4041 \\
\hline 13 & 1.24 & 0.505 & 0.5315 & 1.33 & 0.512 & 0.5159 & 1.4 & 0.560 & 0.4248 \\
\hline 14 & 1.23 & 0.498 & 0.5476 & 1.35 & 0.524 & 0.4912 & 1.45 & 0.531 & 0.4796 \\
\hline 15 & 1.28 & 0.450 & 0.6865 & 1.35 & 0.495 & 0.5578 & 1.37 & 0.812 & 0.1949 \\
\hline 16 & 1.27 & 0.465 & 0.6392 & 1.35 & 0.491 & 0.5673 & 1.43 & 0.468 & 0.5823 \\
\hline 17 & 1.28 & 0.421 & 0.7958 & 1.34 & 0.487 & 0.5777 & 1.43 & 0.466 & 0.6404 \\
\hline 18 & 1.27 & 0.449 & 0.6895 & 1.37 & 0.457 & 0.6682 & 1.39 & 0.571 & 0.4075 \\
\hline 19 & 1.25 & 0.23 & 0.4913 & 1.34 & 0.555 & 0.4323 & 1.43 & 0.491 & 0.5711 \\
\hline 20 & 1.28 & 0.502 & 0.5385 & 1.32 & 0.592 & 0.3766 & 1.43 & 0.491 & 0.5711 \\
\hline 21 & 1.24 & 0.531 & 0.4766 & 1.36 & 0.544 & 0.4525 & 1.39 & 0.569 & 0.4106 \\
\hline 22 & 1.27 & 0.417 & 0.8120 & 1.38 & 0.538 & 0.4648 & 1.39 & 0.538 & 0.4637 \\
\hline 23 & 1.29 & 0.403 & 0.8767 & 1.34 & 0.488 & 0.5758 & 1.41 & 0.535 & 0.4705 \\
\hline 24 & 1.25 & 0.493 & 0.5594 & 1.34 & 0.525 & 0.4902 & 1.40 & 0.575 & 0.4008 \\
\hline 25 & 1.26 & 0.526 & 0.4859 & 1.36 & 0.409 & 0.8502 & 1.40 & 0.513 & 0.5162 \\
\hline 26 & 1.28 & 0.409 & 0.8468 & 1.34 & 0.485 & 0.5826 & 1.42 & 0.507 & 0.5314 \\
\hline 27 & 1.27 & 0.455 & 0.6680 & 1.35 & 0.497 & 0.5522 & 1.42 & 0.549 & 0.4442 \\
\hline 28 & 1.25 & 0.529 & 0.4801 & 1.34 & 0.466 & 0.6383 & 1.39 & 0.532 & 0.4700 \\
\hline 29 & 1.26 & 0.414 & 0.8260 & 1.36 & 0.440 & 0.7247 & 1.35 & 0.596 & 0.3708 \\
\hline 30 & 1.25 & 0.536 & 0.4665 & 1.34 & 0.522 & 0.4962 & 1.43 & 0.522 & 0.4980 \\
\hline
\end{tabular}

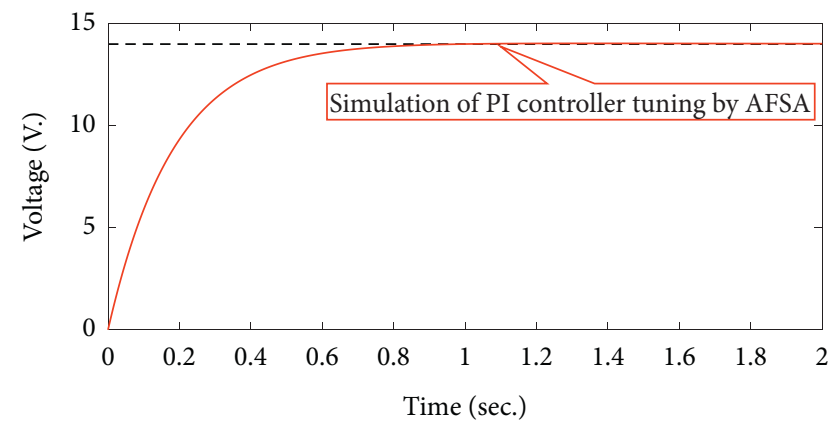

FIGURE 10: Simulation of closed-loop control using PI controller tuned by AFSA.

By substituting the parameters into (29) and (30), the calculation of $K_{P}$ and $T_{i}$ is shown as

$$
\begin{aligned}
K_{p} & =\frac{2 \times 0.707 \times 3.795 \times 0.89-1}{3.54}, \\
T_{i} & =\frac{2 \times 0.707}{3.795} .
\end{aligned}
$$

Consequently, $K_{p}=1.131$ and $T_{i}=0.356$. By substitution into (25),

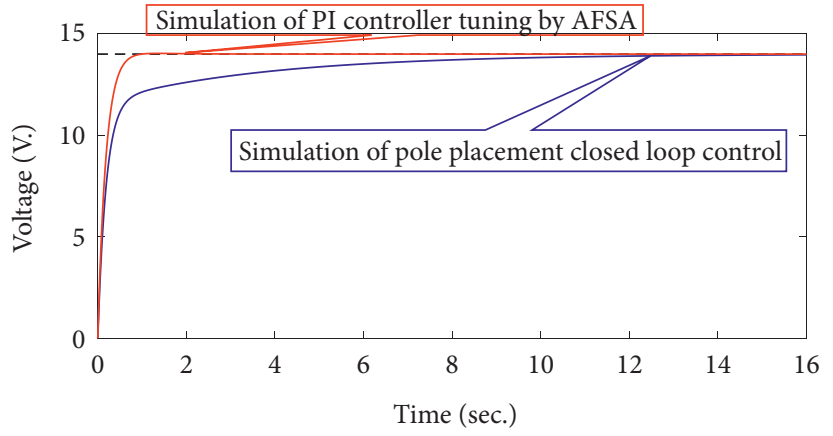

Figure 11: Comparison of the closed-loop control using PI controller designed by pole placement method and tuning by AFSA.

$$
\begin{aligned}
& G \gamma(s)=\frac{(3.54 /(0.89 s+1)) K_{p}\left(1+\left(1 / T_{i} s\right)\right)}{1+(3.54 /(0.89 s+1)) K_{p}\left(1+\left(1 / T_{i} s\right)\right)}, \\
& G \gamma(s)=\frac{\left(K_{p} T_{i} s+K_{p}\right) 3.54}{T_{i} s(0.89 s+1)+\left(K_{p} T_{i} s+K_{p}\right) 3.54}, \\
& G \gamma(s)=\frac{3.54 K_{p} T_{i} s+3.54 K_{p}}{0.89 T_{i} s^{2}+T_{i} s+3.54 K_{p} T_{i} s+3.54 K_{p}} .
\end{aligned}
$$




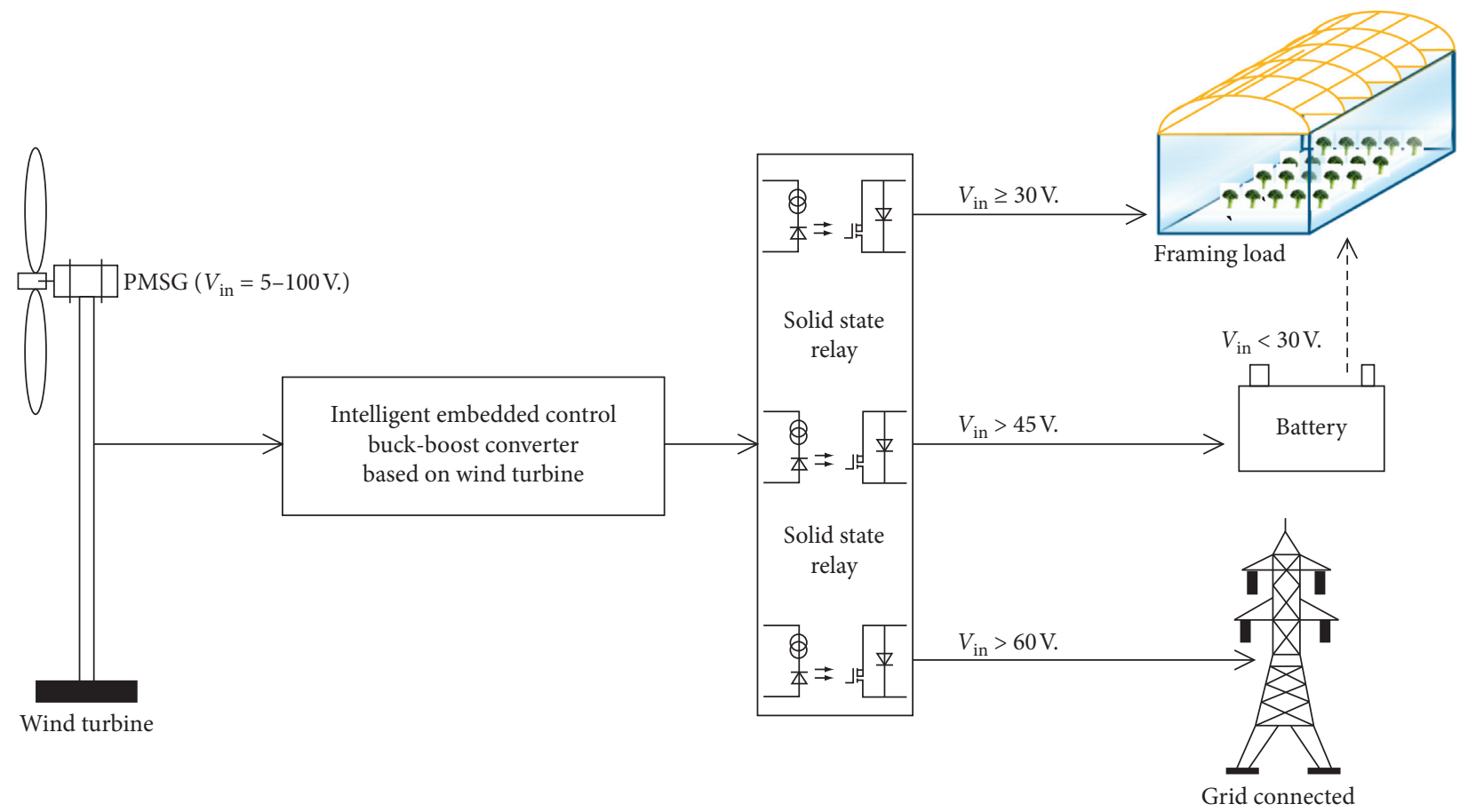

FIGURE 12: Block diagram of the intelligent controller voltage system.

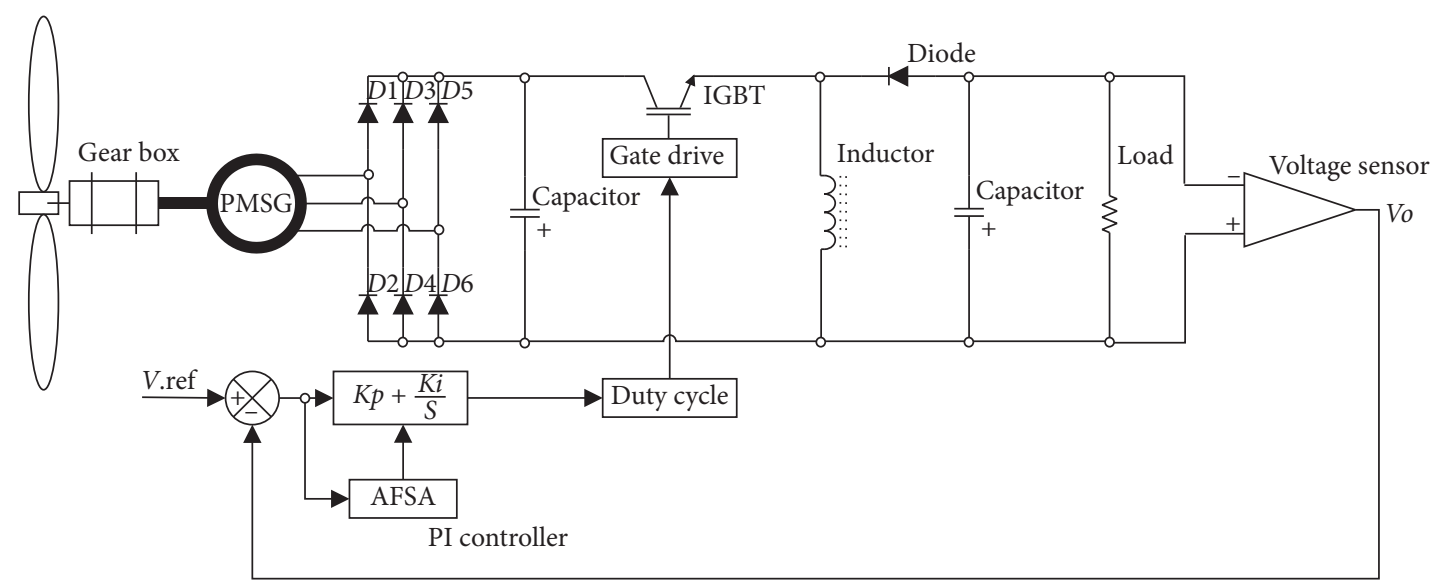

FIGURE 13: PI Control buck-boost converter based on wind turbine system.

Hence, a buck-boost converter design with PI controller is defined as

$$
G \gamma(s)=\frac{3.54 K_{p} T_{i} s+3.54 K_{p}}{0.89 T_{i} s^{2}+\left(3.54 K_{p}+1\right) T_{i} s+3.54 K_{p}} .
$$

The simulation of closed-loop control using PI controller designed by pole placement method via input step command $0-14 \mathrm{~V}$ is shown in Figure 8.

2.1.5. Artificial Fish-Swarm Algorithm (AFSA). AFSA, metaheuristic optimization, is a decision-making process which employs mathematical and logical reasoning in selecting steps reason principle for choosing method or operation until the last step of separating and ordering the operation processes to increase the efficiency of finding and solving problems. Formulation of AFSA is inspired by the behavior of a school of fish, imitating their survival and feeding in nature. The characteristics can be categorized by behavior for finding solutions as follows: [22].

(1) Random behavior: in order to find companion and food, a fish swims randomly in the water

(2) Chasing behavior: if food is discovered by a fish, the others in the neighbourhood go quickly after it

(3) Swarming behavior: in order to guarantee survival of the swarm and avoid dangers from predators, fish move together in schools 


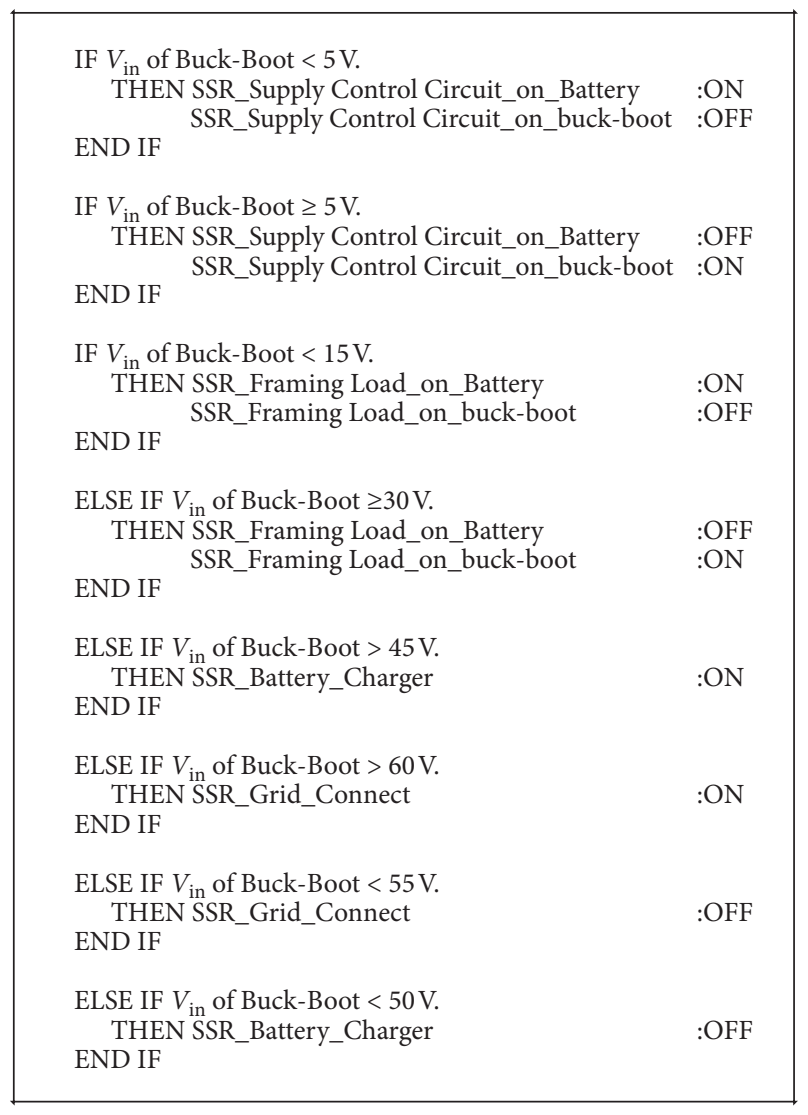

Figure 14: Pseudocode of the load conditions.

(4) Searching behavior: fish go directly and quickly to a region, when more food is discovered, by instinct or vision

(5) Leaping behavior: fish leap to look for food in other regions, when they stagnate in a region

The binary version of AFSA can be given as Figure 9.

Table 2 shows the parameters set for AFSA in tuning the PI controller.

Table 3 show the gains $K_{p}$ and $T_{i}$ in AFSA for the intelligent tuning method for PI controller. From Table 3 , the gains $K_{p}$ and $K_{i}$ are found optimal, using AFSA, at $K_{p}=$ 1.37 and $T_{i}=0.812$ with the minimum cost function of 0.1949 . Thus, the aforementioned values are chosen. The simulation of closed-loop control using PI controller tuned by AFSA via input step command $0-14 \mathrm{~V}$ is shown in Figure 10.

Figure 11 shows the comparison of the closed-loop control, with the output voltage via input step command $0-14 \mathrm{~V}$, using PI controller designed by pole placement method and tuning by AFSA.

\section{Results and Discussion}

3.1. Proposed System. Figure 12 shows the block diagram of an intelligent voltage control system with embedded buckboost converter controller with input from the wind turbine and standard value at $14 \mathrm{~V}$. This is under the following

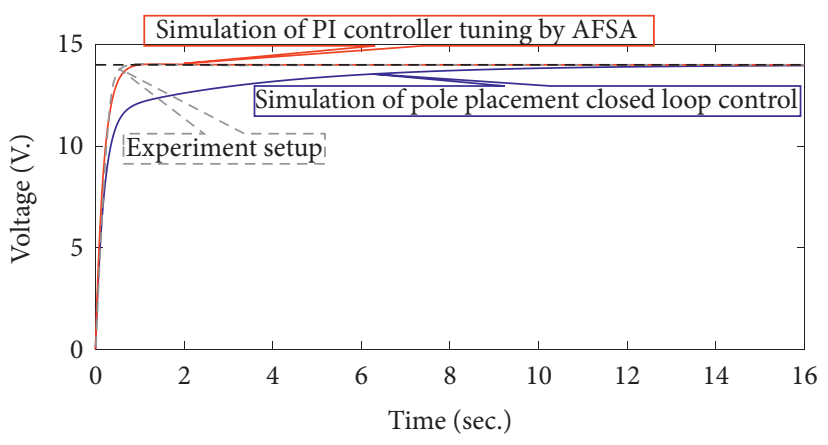

FIGURE 15: Comparison of the experimental and simulation results of the output voltages.

conditions: in case that $V \geq 5$, supply control circuit on buckboost converter; if $V<5$, supply control circuit on battery; when $V \geq 30$, farming system on buck-boost converter; in case that $V<30$, farming system on battery; if $V>4$, battery charger on buck-boost converter; and when $V>60$, gridconnected system on buck-boost converter.

Figure 13 portrays an electricity generating system powered by a wind turbine. The kinetic energy obtained from the wind flowing through the blades of windmill transforms into mechanical energy driving the shaft connected to the PMSG. The obtained alternating voltage is then rectified. Nonetheless, the voltage input to PMSG depends significantly on the fluctuating wind speed. A buck-boost converter, therefore, is used as a control device to ensure a suitable and constant voltage via a PI controller. Furthermore, suitable values of gains $K_{p}$ and $T_{i}$ are achievable via metaheuristic optimization using AFSA, taking into consideration the output voltage from the buck-boost converter $\left(V_{\text {out }}\right)$ and the reference voltage $\left(V_{\text {ref }}\right) . V_{\text {ref }}$ is used in setting $V_{\text {out }}$ via an embedded system using Arduino Mega board.

Arduino Mega is a microcontroller board with ATmega2560 chip, which has 54 digital input/output pins. These include 15 pins used as PWM, 16 pins as analogy inputs, and 4 sets of the UART. The board's crystal frequency is $16 \mathrm{MHz}$. Arduino Mega also enables direct data transfer with computers via the board's USB port. Its design is compatible with various types of shield. This facilitates and fully supports program development on the Arduino platform. The load conditions are coded as shown in Figure 14.

3.2. Simulation and Experimental Results. In Figure 15, the experimental result is compared with the simulation result of the closed-loop control, with the output voltage via input step command $0-14 \mathrm{~V}$, using PI controller designed by pole placement method and tuning by AFSA.

According to Figure 15, the experimental result of the output voltage is tested. In the simulation, the output voltage of proposed system, both tuned gains the PI controller by AFSA and the PI controller using pole placement method, are compared.

Figure 16 shows the experimental setup of the intelligent voltage control system with Arduino Mega board connected to a buck-boost converter using a PI controller adjusted by 


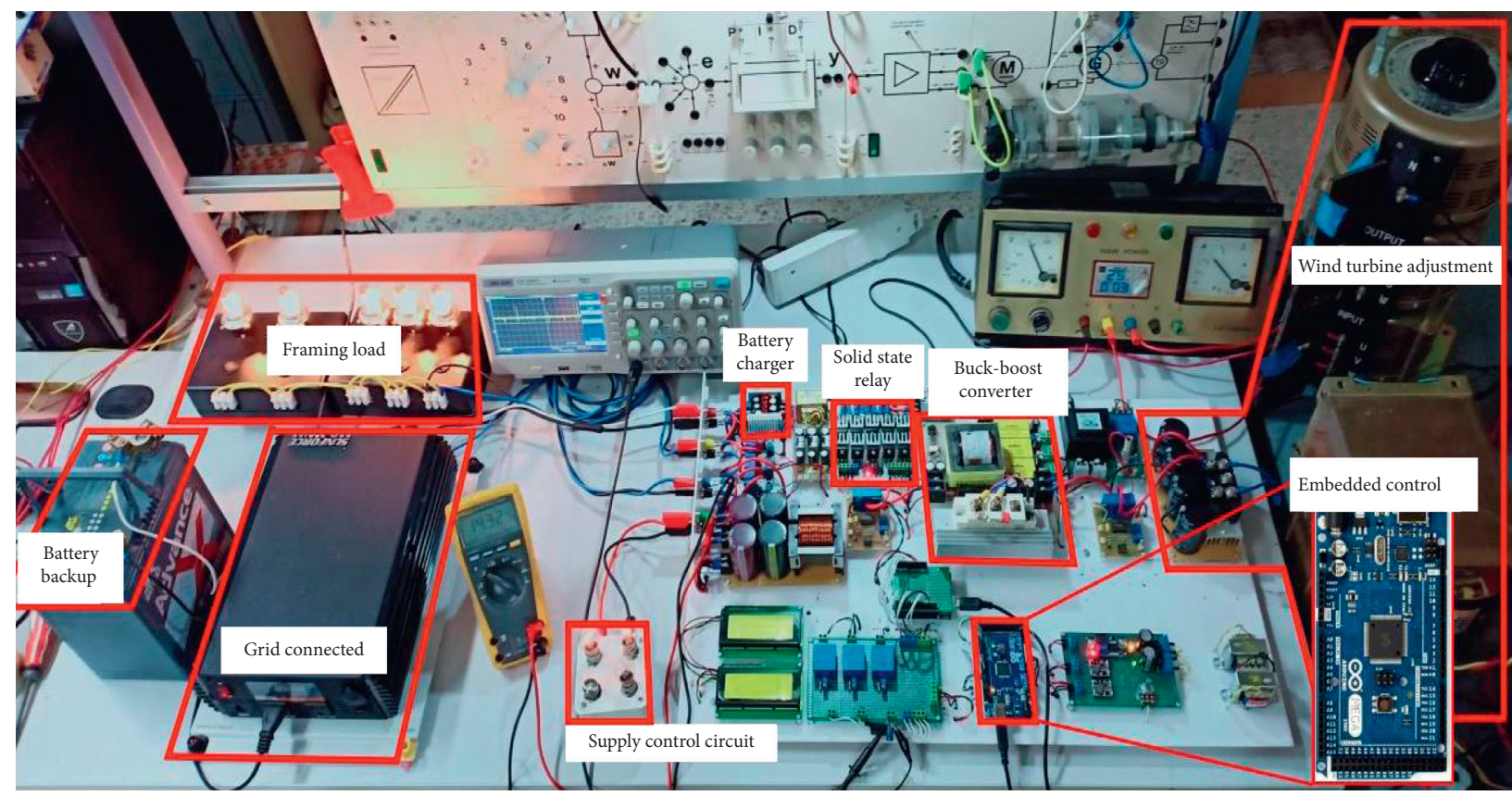

FIGURE 16: Experimental setup of intelligent control of the PI controller based on a buck-boost converter.

AFSA at objective output voltage of $14 \mathrm{~V}$ using PI controller designed by pole placement method and tuning by AFSA. It can control operations of a supply control circuit system, farming load system, battery charger system, and gridconnected system.

In the experiment where the reference output voltage value is set to $14 \mathrm{~V}$, the input supply voltage $\left(V_{\text {in }}\right)$ inconstantly varies from 5 to $100 \mathrm{~V}$, with no load present; the results for closed-loop control using PI controller designed by pole placement method are shown in the following figures.

Figure 17 shows the results of the voltage control system using a buck-boost converter tuning gains of PI controller by pole placement method of closed-loop system at reference voltage of $14 \mathrm{~V}$ with no load, supplying input voltage $\left(V_{\text {in }}\right)$ of $5-100 \mathrm{~V}$. In Figure $17(\mathrm{a})$, the input supply voltage $\left(V_{\text {in }}\right)$ starts from $5 \mathrm{~V}$ to $100 \mathrm{~V}$. Even under step input of $V_{\text {in }}$ changing rapidly, the output response is overshooting with no steady state error. In Figure 17(b), when $V_{\text {in }}$ is constant, $V_{\text {out }}$ is close to the voltage reference at $14 \mathrm{~V}$. Moreover, the experiment testing of input voltage increased from $5 \mathrm{~V}$ to $100 \mathrm{~V}$ and decreased from $100 \mathrm{~V}$ to $5 \mathrm{~V}$, and the output response is close to the voltage reference if the input voltage is constant.

Next, in the experiment where the reference output voltage value is set to $14 \mathrm{~V}$, the input supply voltage $\left(V_{\text {in }}\right)$ inconstantly varies from 5 to $100 \mathrm{~V}$, with no load present; closed-loop control by PI controller tuned by metaheuristic optimization using artificial fish-swarm algorithm (AFSA) is shown in the following figures.

Figure 18 shows the results of the intelligent voltage controlling system via a buck-boost converter by a PI controller tuned by metaheuristic optimization using artificial fish-swarm algorithm (AFSA) at reference voltage of
$14 \mathrm{~V}$ with no load, supplying input voltage $\left(V_{\text {in }}\right)$ of $5-100 \mathrm{~V}$. In Figure 18(a), the input supply voltage $\left(V_{\text {in }}\right)$ starts at $5 \mathrm{~V}$ and gradually increases to $100 \mathrm{~V}$. It is observed that the output voltage $V_{\text {out }}$ remains constant at the reference voltage $\left(V_{\text {ref }}\right), 14 \mathrm{~V}$, throughout. Moreover, another test is implemented on the intelligent voltage control system when the input supply voltage $\left(V_{\text {in }}\right)$ is not constant. Tuning is performed to create continuity. $V_{\text {in }}$ is made equal to $5 \mathrm{~V}$, rising to $100 \mathrm{~V}$, and reduced back to $5 \mathrm{~V}$. The intelligent electrical control system can effectively maintain the voltage $V_{\text {out }}$ at a constant value of 14 Vas shown in Figure 18(b).

According to Figures 17 and 18, showing the output voltage of the experimental result of proposed system, with both tuned gains of the PI controller by a pole placement method and PI controller by AFSA, the results show that the simulation corresponds with the experiment result. In experiment result in a real plant, the comparison results revealed that the response of the output voltage with tuned gains by AFSA of PI controller is more approachable to the reference voltage at $14 \mathrm{~V}$.

Figure 19 shows the experimental results of the intelligent voltage control system when on load. An experiment on the intelligent voltage control system via a buck-boost converter using a PI controller tuned by AFSA at a reference voltage of $14 \mathrm{~V}$ when on load is done. The test is performed with a supply load to the control circuit of $1 \mathrm{~A}$, a farming load system of $10 \mathrm{~A}$, a battery charger system of 12 Vat a current of $5 \mathrm{~A}$, and a gridconnected system of $5 \mathrm{~A}$, under the following conditions: in case that $V_{\text {in }} \geq 5 \mathrm{~V}$, supply control circuit on buck-boost converter; if $V_{\text {in }}<5 \mathrm{~V}$, supply control circuit on battery; when $V_{\text {in }} \geq 30 \mathrm{~V}$, farming system on buck-boost converter; in case that $V_{\text {in }}<30 \mathrm{~V}$, farming system on battery; if $V_{\text {in }}>40 \mathrm{~V}$, battery charger on buck-boost converter; and when $V_{\text {in }}>60 \mathrm{~V}$, grid-connected system on buck-boost converter. 


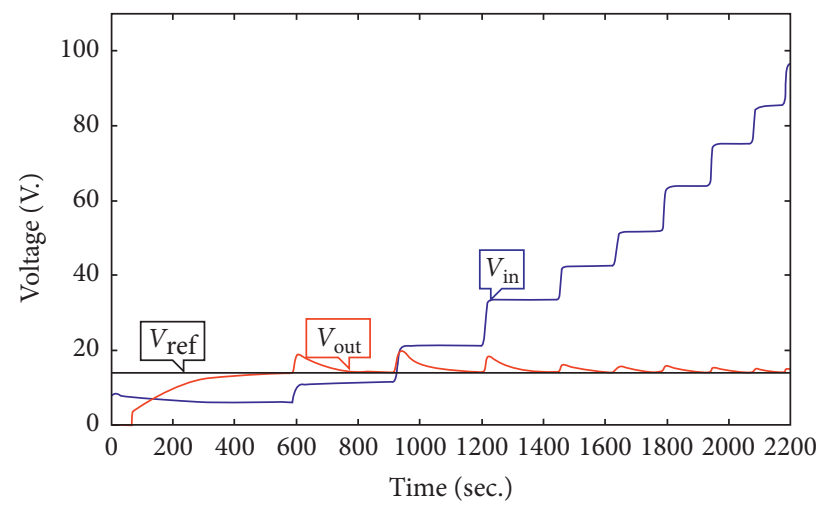

(a)

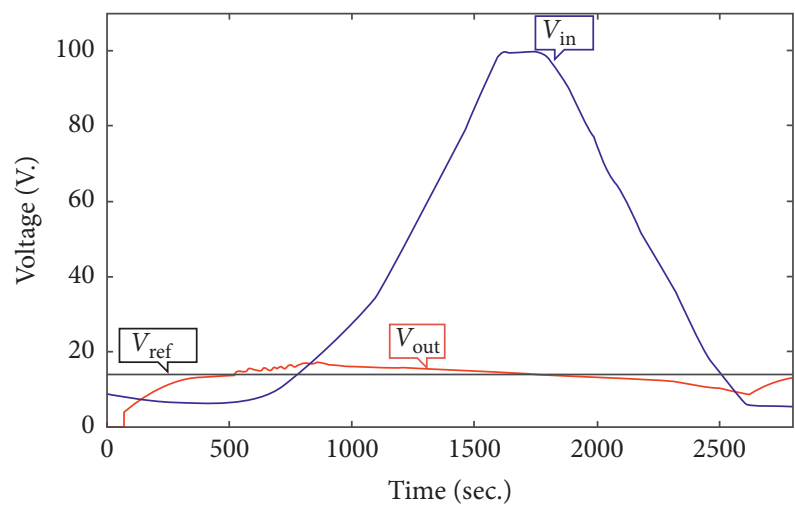

(b)

FIGURE 17: The output voltage response at no load. (a) The input supply voltage stair change varying from 5 to $100 \mathrm{~V}$. (b) The input supply voltage varying from 5 to $100 \mathrm{~V}$

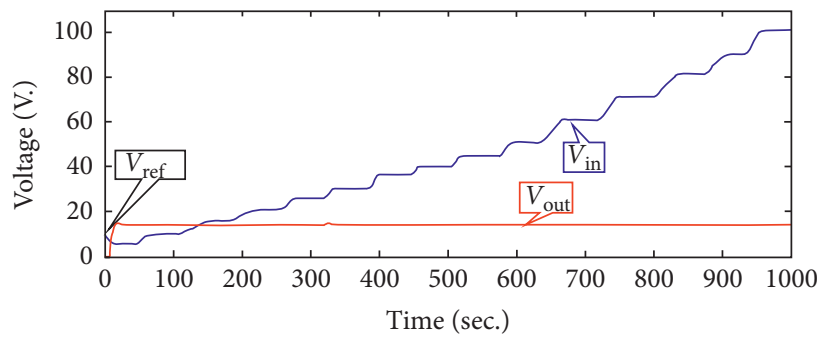

(a)

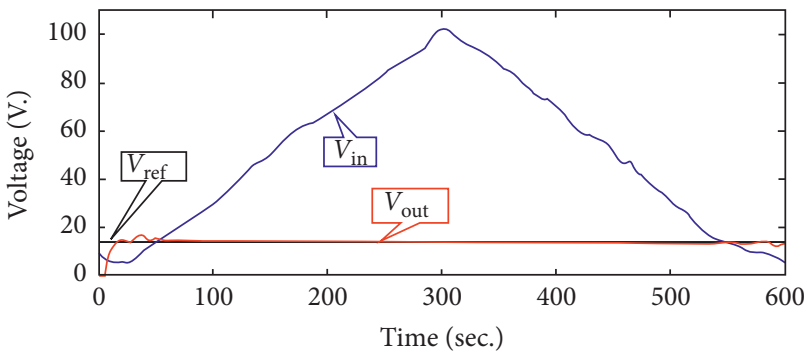

(b)

FIgURE 18: The output voltage response at no load. (a) The input supply voltage stair change varying from 5 to $100 \mathrm{~V}$. (b) The input supply voltage varying from 5 to $100 \mathrm{~V}$.

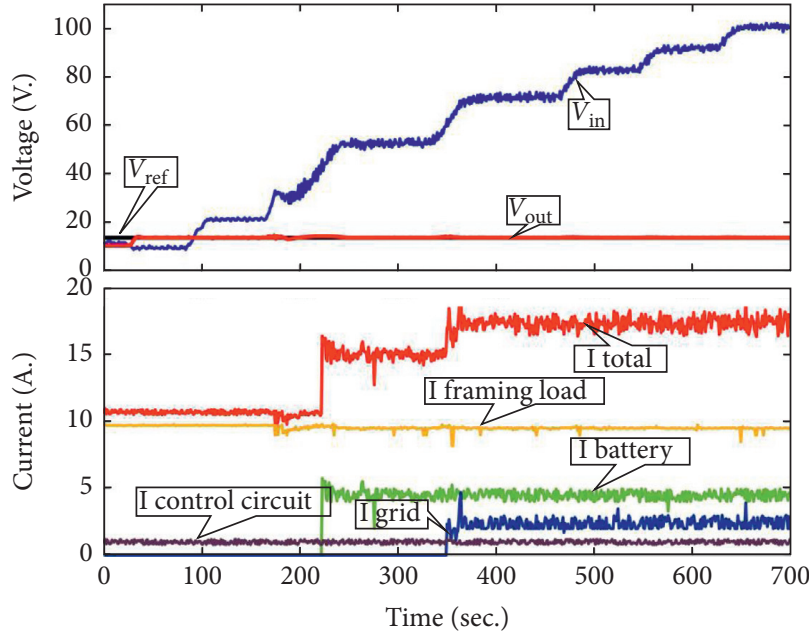

(a)

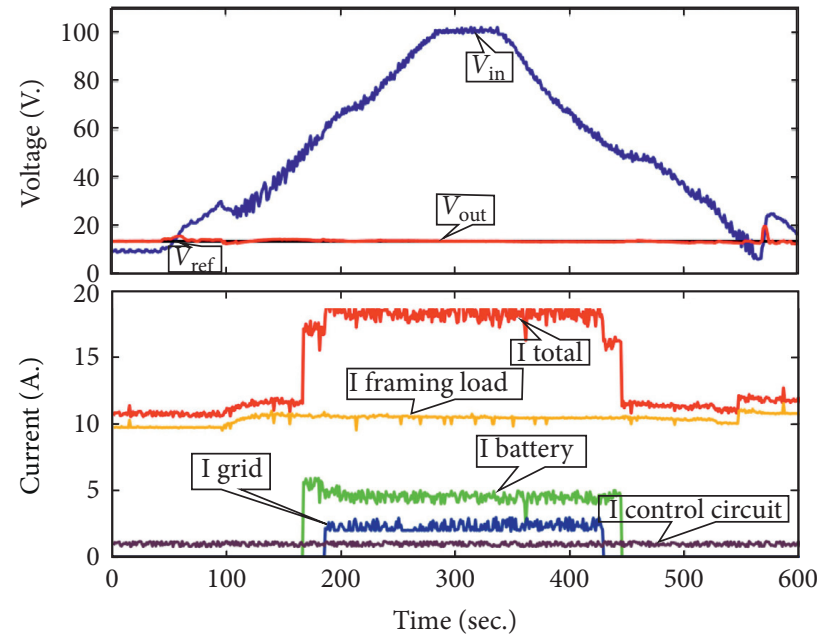

(b)

FIgURE 19: The output voltage response at load. (a) The input supply voltage stair change varying from 5 to $100 \mathrm{~V}$. (b) The input supply voltage varying from 5 to $100 \mathrm{~V}$.

The experimental result is shown in Figure 19(a). When the supplied input voltage $V_{\text {in }}$ stair changes at 5 Vand increases to $100 \mathrm{~V}$, it is found that the intelligent electrical control system is able to maintain the reference voltage at
$14 \mathrm{Vin}$ any condition. $I_{\text {Battery }}$ is activated to the charging current of $5 \mathrm{~A}$ when $V_{\text {in }}>45 \mathrm{~V}$, and $I_{\text {Grid }}$ rises to $2 \mathrm{~A}$ if $V_{\text {in }}>60 \mathrm{~V}$. When the circuit is at full load, the total current $\left(I_{\text {Total }}\right)$ measures approximately $18 \mathrm{~A}$. On the other hand, 
$I_{\text {Control Circuit }}$ and $I_{\text {Farming Load }}$ remain constant as per the condition set. Figure 19(b) shows experimental results of the intelligent voltage control system where the input voltage $V_{\text {in }}$ is not constant. Continuity is acquired by adjusting $V_{\text {in }}$ to $5 \mathrm{~V}$ increasing to $100 \mathrm{~V}$ and decreasing to $5 \mathrm{~V}$. The intelligent voltage control system can efficiently maintain the output voltage $V_{\text {out }}$ at a constant value at the reference voltage of $14 \mathrm{~V}$ as shown in Figure $17(\mathrm{~b})$.

\section{Conclusion}

This research aims to design a buck-boost converter for controlling the output voltage at $14 \mathrm{~V}$ and to develop a PI controller tuned by AFSA, metaheuristic optimization, which is able to use intelligent voltage system of $18 \mathrm{~A}$ load. The result of the experiment shows that the buck-boost converter can withstand the input voltage at 5-100 V using switching frequency $f$ of $4 \mathrm{kHz}$ with inductance $L$ of $33.6 \mathrm{mH}$, capacitance $C$ of 110 uf, load $R$ of $0.78 \Omega$, and duty cycle of $78 \%$. The PI controller tuned by AFSA, metaheuristic optimization, has provided the optimal gains at $K_{p}=1.37$ and $T_{i}=0.812$. It is an effectively intelligent system for controlling system at voltage reference of $14 \mathrm{~V}$ when provided with input voltage in the range 5-100 V and can supply the load of $18 \mathrm{~A}$.

\section{Data Availability}

No data were used to support this study.

\section{Conflicts of Interest}

The authors declare that there are no conflicts of interest regarding the publication of this paper.

\section{Acknowledgments}

The authors would like to thank Dr. Wachirapond Permpoonsinsup, Assistant Professor, Department of Science and Technology, Pathumwan Institute of Technology, for spending her valuable time reading the manuscript and providing valuable suggestions. This study has been supported by the Faculty of Engineering, Pathumwan Institute of Technology, Bangkok, Thailand.

\section{References}

[1] P. Chanjira, W. Permpoonsinsup, and S. Tunyasrirut, "Metaheuristic optimization algorithm for PI control buckboost converter based on wind turbine," International Journal of Pure and Applied Mathematics, vol. 118, no. 20, pp. 473-474, 2018.

[2] N. H. Baharudin, T. M. N. T. Mansur, F. A. Hamid, R. Ali, and M. I. Misrun, "Topologies of DC-DC converter in solar PV applications," Indonesian Journal of Electrical Engineering and Computer Science, vol. 8, no. 2, pp. 368-374, 2017.

[3] S. D. Chandan and V. Chayapathy, "Buck boost converter for small wind turbine," International Journal of Latest Technology in Engineering, Management \& Applied Science, vol. 3, no. $4,2014$.
[4] A. Mittal and K. Arora, "Control of wind energy by using buck-boost converter," International Journal of Emerging Technology and Advanced Engineering, vol. 5, no. 1, 2015.

[5] T. Porselvi and R. Muthu, "Wind energy conversion system with boost converter and CHB MLI with single DC input," International Journal of Engineering and Technology, vol. 6, pp. 0975-4024, 2014.

[6] S. Kamalakkannan and R. Arunkumar, "A double input buck boost converter for wind energy system with power sharing control," International Journal of Power Control and Computation, vol. 7, no. 2, pp. 54-60, 2015.

[7] J. Pakdeeto, R. Chanpittayagit, K. Areerak, and K. Areerak, "The optimal controller design of buck-boost converter by using adaptive Tabu search algorithm based on state-space averaging model," Journal of Electrical Engineering and Technology, vol. 12, no. 3, pp. 1146-1155, 2017.

[8] J. M. Valenzuela and O. G. Alarcon, "On control of a boost DC-DC power converter under constrained input," Complexity, vol. 2017, Article ID 815280, 11 pages, 2017.

[9] R. S. Ortigoza, J. R. G. Sanchez, J. M. A. Martínez et al., “Twostage control design of a buck converter/dc motor system without velocity measurement via a $\Sigma-\Delta$-modulator," Mathematical Problems in Engineering, vol. 2018, Article ID 929316, 11 pages, 2018.

[10] M. A. R. Licea, F. J. P. Pinal, A. I. B. Gutierrez, C. A. H. Ramírez, and J. C. N. Perez, "A reconfigurable buck, boost, and buck-boost converter: unified model and robust controller," Mathematical Problems in Engineering, vol. 2018, Article ID 6251787, 8 pages, 2018.

[11] P. Siano and C. Citro, "Designing fuzzy logic controllers for DC-DC converters using multi-objective particle swarm optimization," Electric Power Systems Research, vol. 112, pp. 74-83, 2014.

[12] A. Jalilvand, A. Kimiyaghalam, A. Ashouri, and H. Kord, "Optimal tuning of PID controller parameters on a DC motor based on advanced particle swarm optimization algorithm," International Journal on Technical and Physical Problems of Engineering Optimization, vol. 3, no. 4, pp. 10-12, 2011.

[13] K. A. Tehrani, A. Amirahmadi, S. M. R. Rafiei et al., "Design of fractional order PID controller for boost converter based on multi-objective optimization," in Proceedings of the 14th International Power Electronics and Motion Control Conference (EPE/PEMC), pp. 3-179, Ohrid, Macedonia, September 2010.

[14] C. H. Liu and Y. Y. Hsu, "Design of a self-tuning PI controller for a STATCOM using particle swarm optimization," Transactions on Industrial Electronics, IEEE, vol. 57, no. 2, pp. 702-715, 2010.

[15] S. M. Çınar and E. Akarslan, "On the design of an intelligent battery charge controller for PV panels," Journal of Engineering Science and Technology Review, vol. 5, no. 4, pp. 30-34, 2012.

[16] H. T. Yau, C. J. Lin, and Q. C. Liang, "PSO based PI controller design for a solar charger system," The Scientific World Journal, vol. 2013, Article ID 815280, 13 pages, 2013.

[17] L. Thananchai, A. Satha, S. Anothai, and T. Prathiphong, $A$ Study on Potential of Wind Energy for Electricity Generation in Central Region of Thailand, National Research Council of Thailand, Bangkok, Thailand, 2013.

[18] A. Ghosh and S. Banerjee, "Design of type-III controller for DC-dc switch-mode boost converter," in Proceedings of the Power India International Conference IEEE, pp. 1-6, Delhi, India, December 2014.

[19] N. D. Benavides, "Power budgeting of a multiple input buckboost converter," IEEE Trans., Power Electron, vol. 20, no. 6, pp. 1303-1309, 2005. 
[20] S. Vijayalakshmi and T. S. R. Raja, "Time domain based digital controller for buck-boost converter," Journal of Electrical Engineering and Technology, vol. 9, no. 5, pp. 1551-1561, 2014.

[21] D. Duman and U. Guvenc, "Determination of the PID controller parameters for speed and position control of DC motor using gravitational search algorithm," in Proceedings of the IEEE 7th International Conference on Electrical and Electronics Engineering, Bursa, Turkey, December 2011.

[22] I. Y. Chung, W. Liu, K. Schoder, and D. A. Cartes, “"Integration of a bi-directional dc-dc converter model into a realtime system simulation of a shipboard medium voltage dc system," Electric Power Systems Research, vol. 81, no. 4, pp. 1051-1059, 2011.

[23] M. A. K. Azad, A. M. A. C. Rocha, and E. M. G. P. Fernandes, "Solving multidimensional 0-1 knapsack problem with an artificial fish swarm algorithm," in Computational Science and Its Applications, pp. 72-86, Springer, Berlin, Germany, 2012. 